\title{
Stereological Assessment of Renal Development in a Baboon Model of Preterm Birth
}

\author{
Megan R. Sutherland Lina Gubhaju M. Jane Black \\ Department of Anatomy and Developmental Biology, Monash University, Clayton, Vic., Australia
}

\section{Key Words}

Baboon $\cdot$ Kidney $\cdot$ Nephron $\cdot$ Preterm birth

\begin{abstract}
At the time when most preterm babies are delivered, nephrogenesis is still ongoing, with the majority of nephrons normally formed during the third trimester of pregnancy. The extrauterine environment, however, is suboptimal for organogenesis, and therefore renal development is likely to be adversely affected by preterm birth. In the long-term, there is emerging evidence of high blood pressure and renal dysfunction amongst young adults born preterm. There is little knowledge to date, however, regarding the effects of preterm birth on renal structural development, perhaps due to the lack of an appropriate animal model. We have demonstrated that the baboon (Papio sp.) has a similar time course of nephrogenesis as the human kidney, and the baboon neonate can also be cared for in the same manner as a human neonate following preterm birth. Through a series of studies assessing renal development in the baboon model of preterm birth, involving the use of gold-standard stereological techniques, we have demonstrated that nephron endowment in the preterm baboon kidney is not reduced. Furthermore, antenatal glucocorticoid exposure prior to preterm delivery was associated with an increase in mature neph-
\end{abstract}

rons. There was, however, evidence of morphological abnormalities in a variable percentage of the glomeruli formed ex utero. Further research is therefore essential in order to establish what factors are involved in contributing to the glomerular abnormalities, and to identify ways in which 'normal' renal development can be conserved and optimised in the extrauterine setting.

Copyright $\odot 2011$ S. Karger AG, Basel

\section{Introduction}

Preterm birth (birth prior to 37 completed weeks of gestation) is a significant medical problem worldwide, with up to $13 \%$ of babies born preterm in the USA [1], and $8 \%$ in Australia [2]; incidence rates have increased $14 \%$ in the USA since 1990 [3]. Due to advances in clinical care practices, the survival of preterm neonates is now as high as $80 \%$ in babies born as early as 25 weeks of gestation [4, $5]$. Birth at a young gestational age is, however, associated with significant morbidity, primarily due to organ immaturity [6]. Importantly, emerging epidemiological research has also indicated that preterm birth is linked to the development of disease in adulthood. Strong associations between low gestational age at birth and high blood pressure [7-17] as well as some evidence of renal dysfunc-

\section{KARGER \\ Fax +4161306 1234 \\ E-Mail karger@karger.ch}

www.karger.com (c) $2011 \mathrm{~S}$. Karger AG, Basel

0250-8095/11/0337-0025\$38.00/0

Accessible online at:

www.karger.com/ajn
Assoc. Prof. M. Jane Black

Department of Anatomy and Developmental Biology

Building 76, Level 3, Monash University

Clayton, VIC 3800 (Australia)

Tel. +61 39902 9112, E-Mail Jane.Black@ med.monash.edu.au 

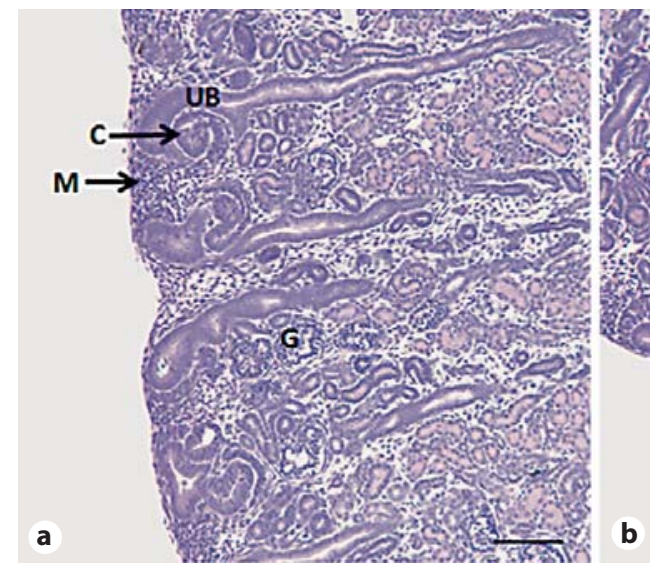

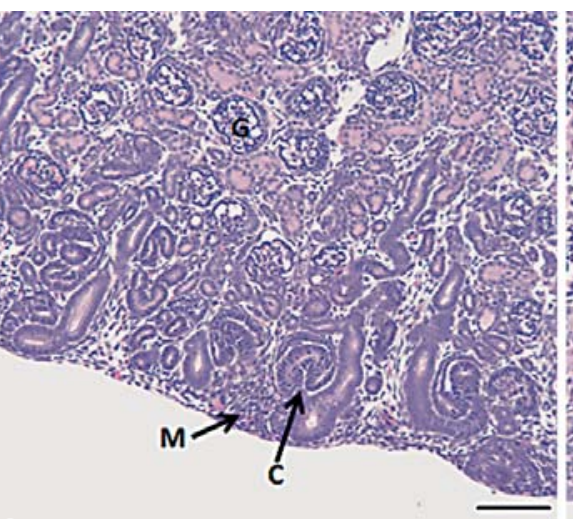

b

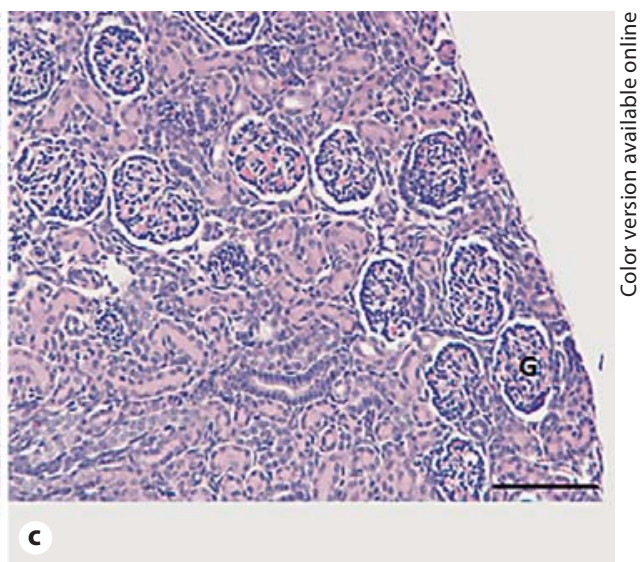

Fig. 1. Photomicrographs demonstrating the time course of nephrogenesis in the fetal baboon kidney. a At 125 days of gestation, there is a wide active nephrogenic zone in the outer renal cortex. b At 140 days of gestation, nephrogenesis is still ongoing as evidenced by the presence of an active nephrogenic zone. c By
175 days of gestation, nephrogenesis is complete with only mature glomeruli located in the superficial layer of the renal cortex. $\mathrm{C}=$ Comma-shaped body; $\mathrm{G}=$ mature glomerulus; $\mathrm{M}=$ metanephric mesenchyme; $\mathrm{UB}=$ ureteric bud. $\mathrm{Bar}=100 \mu \mathrm{m}$. tion [18-20] suggest the possibility that an impairment in renal development may be underlying these conditions. Nephrogenesis is ongoing until approximately 36 weeks of gestation and is therefore completed before birth in the term infant. The majority of nephrons (approximately $60 \%$ ) are formed during the third trimester of pregnancy [21]; this coincides with the timing of preterm birth. Therefore, it is conceivable that renal development is adversely affected in infants born prior to the completion of nephrogenesis, with the final stages of nephrogenesis undertaken in the extrauterine environment.

The renal structural consequences of preterm delivery still remain relatively unknown, perhaps due to the lack of an appropriate animal model. Therefore, the purpose of this review is to provide an overview of recent stereological studies of renal development in a baboon model of preterm birth. These findings highlight the importance of continued research in this area, and demonstrate the advantages of utilising the baboon model in renal development research.

\section{The Baboon as a Model of Human Renal Development}

Through stereological analyses, we have demonstrated that the baboon (Papio sp.) is an ideal animal model for studies of renal development [22]. Similar to the human, the baboon has a relatively long gestation period (approximately 185 days). Furthermore, the ontogeny of organs such as the kidney is very similar to the human [23].

Embryological studies of baboon development determined that nephron formation begins at approximately day 30 of gestation [23], which coincides with the timing of initial ureteric branching in the human kidney [24]. Examination of renal histological sections from baboon fetuses, at varying time points in gestation, further highlighted the parallels in the time course of nephrogenesis between humans and baboons [22]. Nephrogenesis was shown to be ongoing at 125 and 140 days of gestation, with the presence of an active nephrogenic zone (branching ureteric bud and metanephric mesenchyme) in the outer renal cortex, but complete by 175 days, prior to term birth (fig. 1).

In our laboratory, nephron number (a key measure of renal functional capacity) was determined at the later stages of gestation using the physical disector/fractionator approach (described in a later section), which is the gold-standard stereological technique for the unbiased determination of nephron endowment $[25,26]$. In fetal baboons at 125 days of gestation, the beginning of the third trimester of pregnancy, nephron endowment averaged at 115,526 per kidney. By 140 days of gestation, nephron number had increased to $>160,000$ [22]. In baboons where nephrogenesis had been completed (175 and 185 days gestation), total nephron endowment averaged at 284,804 per kidney. There was a strong correlation be- 
tween nephron number and kidney weight in the baboon suggesting that renal size is a determinant of nephron number.

Importantly, nephron number at 125 days of gestation averaged at less than half of the total reached by the completion of nephrogenesis [22]. Therefore, similar to the human kidney, the majority of nephrons are formed during the final trimester of pregnancy. Given the similarities in the time course of nephrogenesis between the baboon and the human, the baboon is therefore an ideal model for research into the effects of preterm birth on the kidney.

\section{The Need for an Animal Model of Preterm Birth}

There has been just one study published to date (besides case studies) that has reported on the renal structural effects of preterm birth in the human neonate. In this autopsy study by Rodriguez et al. [27], the kidneys of preterm neonates, with varying lengths of postnatal survival, were examined using histomorphometric techniques. Results of these analyses indicated that preterm neonates had a significantly reduced number of medullary ray glomerular generations (an index of nephron endowment [28]) compared to term-born controls; this is potentially indicative of a nephron deficit.

There are difficulties in interpreting these results, however, due to the inherent confounders associated with conducting a human autopsy study. These include intrauterine and extrauterine growth restriction of the neonate, unknown maternal nutritional status and drug use, and the use of an intrinsically ill non-surviving population, all factors which are likely associated with impaired renal development and function in the neonate $[29,30]$. Therefore, the use of an appropriate animal model and comprehensive stereological techniques are essential in order to eliminate these confounders and identify the specific effects of preterm birth on renal development.

At the Southwest Foundation for Biomedical Research (San Antonio, Tex., USA), a baboon model of preterm birth was developed. Prior to preterm delivery (48 and $24 \mathrm{~h}$ ), pregnant dams were administered $6 \mathrm{mg}$ of betamethasone. Baboon neonates were then delivered by caesarean section at 125 days (67\%) of gestation, which is equivalent to approximately 27 weeks of gestation in humans. Maternal nutrition was consistently maintained, with all neonates born at an appropriate weight for gestational age. Gestational control animals were delivered and euthanized at 125, 146 and 175/185 days of gestation.
Further preterm baboon neonates were maintained postnatally and euthanised on day 6, 14 or 21 of life. Importantly, baboon neonates (weighing approximately $1 \mathrm{~kg}$ at term) are of a similar size to human preterm neonates, which enables the replication of existing intensive care techniques in their postnatal care.

The practice of rapid weaning from ventilatory support, early introduction of parenteral nutrition, and minimal handling were used in the care of the preterm baboon neonates [31]. Briefly, neonates were intubated following delivery, administered surfactant and ventilated with a humidified pressure-limited and time-cycled ventilator. Extubation to nasal continuous positive airway pressure was attempted at $24 \mathrm{~h}$ of age. Parenteral nutrition was initiated at $24 \mathrm{~h}$ of life and if clinically stable, enteral nutrition was introduced on day 7. Serum electrolytes, glucose, and haematocrit were maintained within the normal range for the extremely-low-birth-weight infant. None of the animals had any identifiable urinary tract anomalies or obstructions, and all were in relatively good health at the time of necropsy. For a more detailed report on the neonatal care of the baboons, see Thomson et al. [31].

\section{Stereological Assessment of Renal Development}

Given that nephrogenesis is ongoing at the time of preterm delivery in the baboon neonate, with the majority of nephrons normally formed during the final trimester of pregnancy [22], we hypothesised that nephrogenesis would be adversely affected by preterm birth. Therefore, we utilised various stereologic and histomorphometric techniques to assess glomerular generation number, the percentage of abnormal glomeruli, nephron number, kidney volume and renal corpuscle volume [22, 32, 33].

At necropsy, the baboon kidneys were excised, cut into quarters along the coronal and horizontal planes, and immersion fixed. The kidney quarters were then sampled using the fractionator principle [34]. Each quarter was sliced into 2-mm slices, and every 2 nd slice (sampling fraction $F_{1}$ ) was embedded in glycol methacrylate resin (1 slice per resin block). The glycol methacrylate blocks were serially sectioned at $20 \mu \mathrm{m}$; every 10th pair of sections (sampling fraction $F_{2}$ ), commencing at a random starting point between 1 and 10 (for example, sections numbered $6,7,16,17,26$ and 27), was collected and stained with haematoxylin and eosin. Total kidney volume $\left(V_{k i d}\right)$ was then estimated using the Cavalieri principle [35]. To do this, every 10th section was viewed using a microfiche reader, with the projected image overlaid by a $2 \times 2 \mathrm{~cm}$ unbiased 


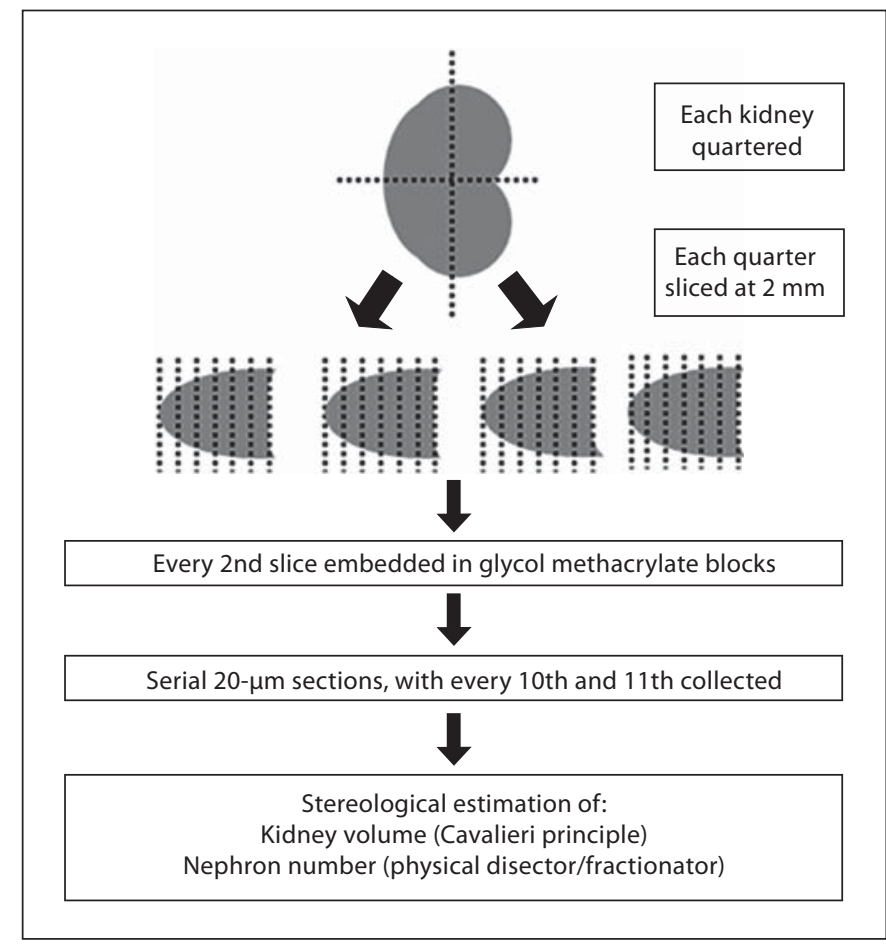

orthogonal grid. The number of intersecting grid points overlaying the kidney tissue on each section was recorded, and total kidney volume was then estimated using the following equation:

$$
V_{k i d}=\frac{1}{F_{1}} \times \frac{1}{F_{2}} \times t \times a(p)_{M} \times P_{s}
$$

where $1 / F_{1}$ and $1 / F_{2}$ are the inverse sampling fractions at each level of tissue sampling; $t$ is the thickness of the sections; $a(p)_{M}$ is the area associated with each intersecting grid point, and $P_{s}$ is the total number of intersecting points counted per kidney. The number of intersecting grid points overlaying one intact section per slice to be used in the estimation of nephron number was also recorded as $P_{f}$.

Total nephron number was estimated using the physical disector technique. This is an unbiased approach whereby each glomerulus (regardless of size, shape and position) has an equal chance of being sampled $[25,26]$. Two modified microscopes with projection arms were used to compare images of paired 10th and 11th histological sections (one completely intact pair of sections per slice of kidney sampled; approximately 8 per kidney). Paired images were projected onto two identical and unbiased 64-point counting frames (fig. 2). Paired kidney sections were systematically sampled (commencing at a

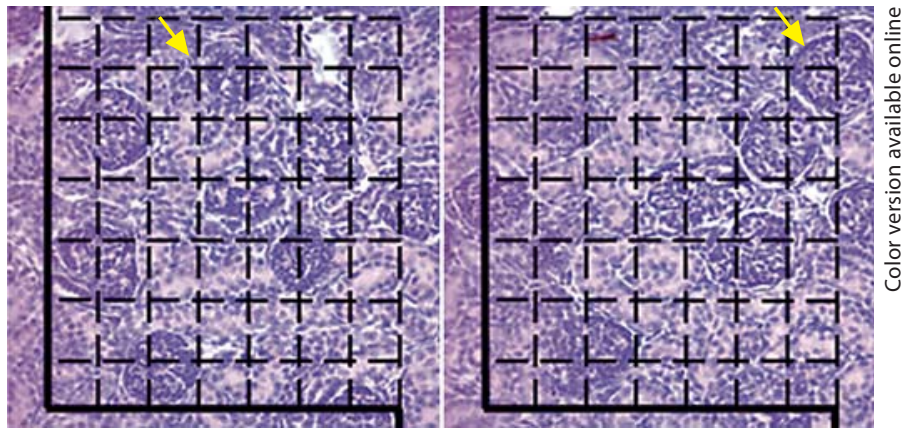

Fig. 2. The physical disector/fractionator technique was used for the estimation of nephron endowment. a The stages of tissue sampling using the fractionator principle for the estimation of kidney volume (using the Cavalieri principle) and nephron number (using the physical disector/fractionator technique). b Representative adjacent 10th and 11th baboon kidney sections overlaid with unbiased 64-point counting frames. The two sections were compared and mature glomeruli were counted if they were present in the section on the right and not on the left, and vice versa, within the unbiased counting frames (partly or wholly within the dashed lines and not touching the bold lines). The glomeruli counted (indicated by arrows; $Q^{-}$) were used in the estimation of nephron number using the physical disector/fractionator approach.

random starting point at the top of the section) in a uniform pattern along the $\mathrm{x}$ - and $\mathrm{y}$-axis. At each field of view, the number of intersecting grid points overlaying the kidney tissue $\left(P_{k i d}\right)$ and renal corpuscles $\left(P_{\text {corp }}\right)$ were recorded. The number of glomeruli present in the projected image of the 10th section, but not in the matched 11th section (within the parameters of the unbiased counting frame) and vice versa is recorded as a total of $Q^{-}$at each field of view. Importantly, only mature glomeruli were counted, with developing structures such as comma- and S-shaped bodies being excluded. The total number of glomeruli in the kidney $\left(N_{\text {glom }}\right)$ was estimated using the following calculation:

$$
N_{\text {glom }}=\frac{1}{F_{1}} \times \frac{1}{F_{2}} \times \frac{P_{s}}{P_{f}} \times \frac{1}{2 f_{a}} \times Q^{-}
$$

where $1 / F_{1}$ and $1 / F_{2}$ refer to the inverse sampling fractions at each level of tissue sampling; $P_{s} / P_{f}$ is the inverse of the sampling fraction relating to the kidney sections analysed; $Q^{-}$is the total number of glomeruli counted per kidney, and $1 / 2 f_{a}$ is the inverse of the fraction of the total tissue area used to count glomeruli, where $f_{a}$ is calculated in the following manner:

$$
f_{a}=\frac{P_{k i d} \times a(p)_{P D}}{P_{f} \times a(p)_{M}}
$$


$P_{k i d}$ is the total number of intersecting grid points counted per kidney; $a(p)_{P D}$ is the area associated with each intersecting grid point used with the physical disector; $P_{f}$ is the number of intersecting grid points on the one intact section per slice of kidney used with the physical disector, and $a(p)_{M}$ is the area associated with each grid point used on the microfiche.

The mean renal corpuscle volume $\left(V_{\text {corp }}\right)$ was calculated by dividing the volume density of the renal corpuscle by the numerical density of renal corpuscles within the kidney:

$$
V_{\text {corp }}=\frac{P_{\text {corp }}}{P_{\text {kid }}} \div \frac{N_{\text {glom }}}{V_{\text {kid }}}
$$

During the assessment of nephron number, the number of morphologically abnormal and normal glomeruli was also recorded at each field of view. The total percentage of abnormal glomeruli (exhibiting an enlarged Bowman's space and shrunken glomerular tuft) was then calculated per kidney.

This comprehensive assessment of renal development was possible due to whole kidneys (or a known fraction of the kidney) being available for analysis; this is often not the case following human autopsy. The medullary ray glomerular generation counting method is a useful technique for the assessment of nephrogenesis in the absence of whole kidneys [28]. This method involves identifying clearly distinguishable medullary rays in histological renal sections, and counting all developed glomeruli along one side of the ray, in a line from the inner to outer renal cortex. In our baboon studies, we have found a strong correlation between glomerular generation number and nephron number, which supports the validity of the technique (fig. 3).

\section{The Effects of Preterm Birth on Renal Development}

Our recently published data from stereological analyses of the preterm baboon kidney [32] indicated that, in comparison to age-matched gestational controls, there was no significant difference in nephron number or glomerular generation number in the preterm kidney (fig. 4); this is in contrast to the findings from the previously published human autopsy study by Rodriguez et al. [27]. Nephron number in the preterm baboon kidney appeared to be within the normal range, albeit at the lower end; however, nephrogenesis was still ongoing at the time of analysis, so nephron number was expected to increase further before the completion of nephrogenesis. This difference in results compared to the previously published

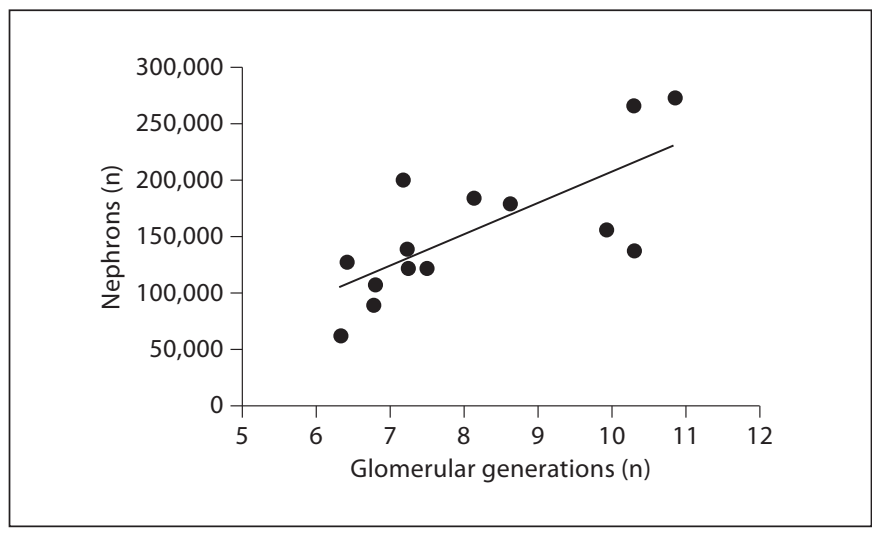

Fig. 3. There is a significant linear correlation between glomerular generation number and nephron number $\left(\mathrm{R}^{2}=0.536, \mathrm{p}=\right.$ 0.003 ) in the developing baboon kidney (derived from Gubhaju et al. [22]).

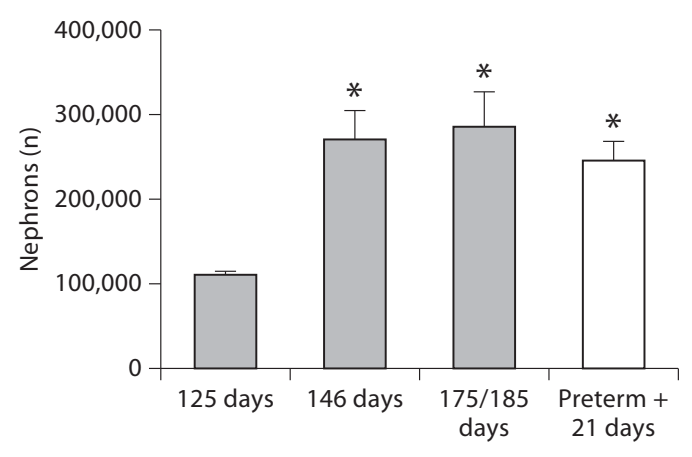

Fig. 4. Average nephron numbers in fetal baboons at 125, 146 and $175 / 185$ days of gestation, and in preterm baboons on postnatal day 21. Nephron number had significantly increased since the time of delivery in the preterm group; however, it was not significantly different to the age-matched gestational controls (146 days) and term (175/185 days) controls (derived from Gubhaju et al. $[32]) .{ }^{*} \mathrm{p}<0.05$ vs. the 125 -day group.

autopsy study [27] is likely due to their inclusion of intrauterine-growth-restricted neonates, a factor known to significantly impair nephrogenesis [36, 37].

There was substantial kidney growth in the postnatal period following preterm delivery, with significantly larger kidneys in relation to body weight in the preterm baboon compared to age-matched gestational controls [32]. Importantly, the strong correlation between nephron number and kidney weight/volume (noted in previous studies in the baboon [22]) was maintained in the 


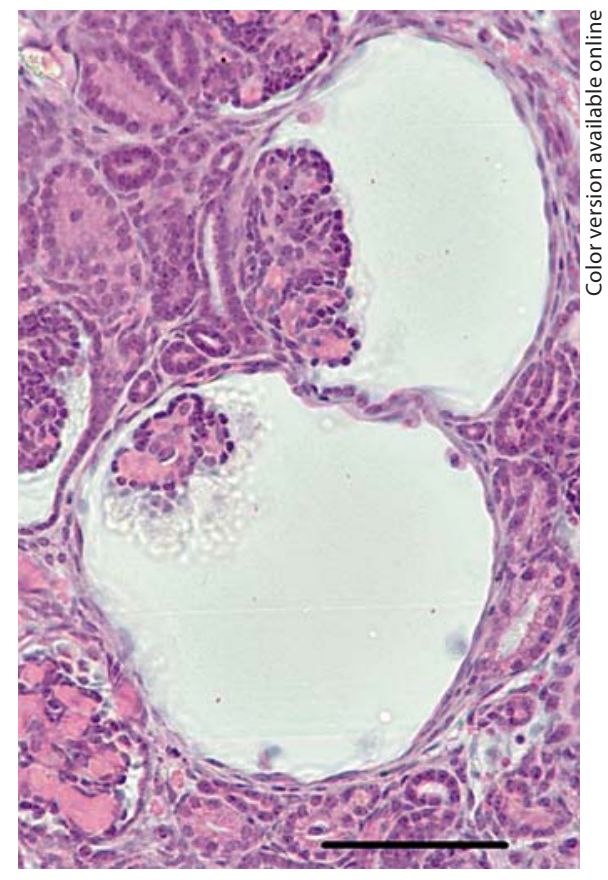

Fig. 5. Representative photomicrograph of abnormal glomeruli (with shrunken glomerular tufts and dilated Bowman's spaces) in the outer renal cortex of a preterm baboon kidney. Bar $=100 \mu \mathrm{m}$.

preterm kidney [32]. However, glomerular density (number of glomeruli per gram of kidney tissue) was significantly reduced in the preterm kidney $(83,840$ glomeruli/g) compared to controls $(193,400$ glomeruli/g). Given that total nephron number was not reduced and renal corpuscle size not affected [32], the reduction in glomerular density most likely reflects a postnatal increase in tubular or interstitial mass.

Of major concern, a significant proportion of morphologically abnormal glomeruli, which exhibited an enlarged Bowman's space and shrunken glomerular tuft, were commonly noted in the outer renal cortex of the preterm baboon kidney (fig. 5) [32]. Similar findings have been reported in the human preterm kidney [27]. Importantly, given the localisation of the affected glomeruli in the outer renal cortex, it is likely that it is those glomeruli that are newly formed in the extrauterine environment that are vulnerable.

There was a large variability between neonates in the proportion of abnormal glomeruli present, ranging from 0.2 to $18.3 \%$ [32]. This suggests that the abnormalities may not have occurred as a result of preterm birth per se, but are likely related to factors in their postnatal care, which varied between individual neonates. For example, neonatal exposure to nephrotoxic medications (such as non-steroidal anti-inflammatory drugs and antibiotics) has been associated with both structural and functional renal injury [38]. However, a specific factor attributing to the abnormal glomeruli has not yet been established. Given the extent of the abnormality, it is likely that the affected glomeruli will never become functional, perhaps resulting in a deficit of functional nephrons, as noted in the human preterm kidney by Rodriguez et al. [27].

\section{Antenatal Glucocorticoid Administration}

One factor which is commonly used in the care of the preterm neonate is the administration of antenatal glucocorticoids. In clinical practice, the glucocorticoids betamethasone or dexamethasone are administered to pregnant women at risk of preterm delivery in order to accelerate fetal lung maturation [39]. Importantly, exposure to glucocorticoids antenatally is also associated with increased mean arterial blood pressure, renal blood flow and glomerular filtration rate [40-46], suggesting that accelerated renal functional maturation also occurs.

Through previous stereological analyses using animal models such as the rodent [47-49] and sheep [50], studies have indicated that a reduced nephron endowment in offspring is associated with antenatal glucocorticoid exposure. Furthermore, a recent study by de Vries et al. [51] found postnatal administration of dexamethasone in the neonatal rat (at a time of ongoing nephrogenesis) led to a reduction in glomerular density. Our studies in the preterm baboon model involved replication of the clinical setting, with $0.4 \mathrm{ml} / \mathrm{kg} /$ day of betamethasone administered to pregnant baboons 48 and $24 \mathrm{~h}$ prior to delivery [32]. Assessment of the kidneys from these offspring, at 125 days of gestation (the time of caesarean section delivery) and 21 days postnatally, demonstrated that nephron endowment was not adversely affected by steroid exposure. Importantly, structural evidence of enhanced renal maturation was evident, with an increase in the number of mature nephrons present in the steroidexposed kidneys compared to those that were not exposed (fig. 6) [32]; this parallels the findings of increased renal functional capacity following antenatal glucocorticoid exposure. These results imply that renal development is not likely to be adversely affected in the short term by this common clinical procedure, which is vital for postnatal survival of the preterm infant. As nephrogenesis was still ongoing at the time of assessment, however, it is unknown whether there are long-term effects 


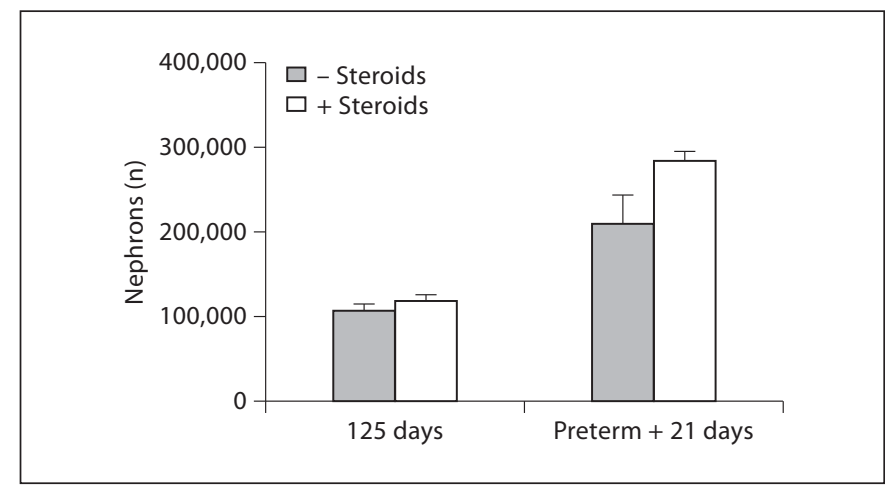

Fig. 6. Average nephron number in fetal baboons at 125 days of gestation and in preterm baboons on postnatal day 21 that were exposed or not exposed to antenatal steroids. Two-way ANOVA analysis determined that antenatal steroid exposure $(\mathrm{p}=0.03)$ and increased postnatal age $(\mathrm{p}<0.0001)$ were both associated with a significant increase in nephron endowment (derived from Gubhaju et al. [32]).

of the accelerated renal maturation, such as the early cessation of nephrogenesis, which may influence total nephron endowment.

\section{Postnatal Retinoic Acid Administration}

It can be hypothesised that a preterm kidney with a large proportion of abnormal glomeruli may ultimately suffer a nephron deficit, hence it is important to maximise nephron endowment in the preterm infant. Theoretically, there is a critical 'window of opportunity' in the early postnatal period following preterm birth whereby interventional strategies may be implemented in order to enhance nephrogenesis. One potential strategy that has been investigated was the administration of retinoic acid, the active metabolite of vitamin A. Importantly, vitamin A administration is already being trialled in preterm infants due to successful outcomes in reducing neonatal morbidity and mortality [52]. In the kidney, the administration of retinoic acid upregulates the expression of the c-ret tyrosine kinase receptor, resulting in an increase in ureteric bud branching and thereby increasing the number of nephrons formed $[53,54]$. Importantly, the antenatal administration of retinoic acid in a rodent model resulted in augmented nephron endowment in the offspring, even to supernumerary levels [55], and furthermore subjugated the nephron deficit expected in offspring with simultaneously imposed intrauterine growth restriction [56].
In the baboon model of preterm birth, $500 \mu \mathrm{g} / \mathrm{kg}$ of retinoic acid was administered daily to neonates following preterm delivery at 125 days of gestation. Through stereological analyses of renal development in the 21-dayold preterm baboons, it was determined that postnatal retinoic acid administration did not influence total nephron number or the number of glomerular generations. This lack of effect of retinoic acid on nephron endowment is likely due to the late timing of administration. In the human kidney, ureteric bud branching is completed by approximately 22 weeks of gestation [57] (near the borderline of viability in the preterm infant), therefore only exposure to retinoic acid prior to this time would be likely to enhance nephrogenesis. Therefore, any postnatal interventional strategies in the preterm infant must be focused on the later stages of renal development, such as glomerular generation formation, rather than on the period of branching morphogenesis.

\section{Conclusion}

We have shown through a series of stereological studies, conducted using a clinically relevant baboon model, that nephrogenesis continues following preterm birth; however, it may be impaired with evidence of morphological glomerular abnormalities in the outer cortex of some, but not all, preterm kidneys. Importantly, antenatal glucocorticoid exposure prior to preterm birth is associated with accelerated renal maturity, which may impart a benefit on renal function in the early postnatal period. It is essential that future research be focused on determining which factors in the postnatal care of the preterm infant result in impaired renal development, and on ways in which to provide the optimal environment in the neonatal intensive care unit for postnatal organogenesis to occur.

\section{Acknowledgements}

We wish to acknowledge Prof. Jacqueline Coalson and Ms. Vicki Winter for providing the baboon kidney tissue, and Prof. Bradley Yoder for providing the neonatal clinical data and for his expertise and advice during this project. This research was supported by the National Health and Medical Research Council of Australia.

\section{Disclosure Statement}

The authors have no conflicts of interest to disclose. 


\section{References}

$>1$ Goldenberg R, Culhane J, Iams J, Romero R: Epidemiology and causes of preterm birth. Lancet 2008;371:75-84.

2 Laws P, Abeywardana S, Walker J, Sullivan E: Australia's mothers and babies 2007 Sydney, AIHW National Perinatal Statistics Unit, 2009

-3 Heron M, Sutton P, Xu J, Ventura S, Strobino D, Guyer B: Annual summary of vital statistics: 2007. Pediatrics 2010;125:4-15.

$\checkmark 4$ Noble L: Developments in neonatal technology continue to improve infant outcomes. Pediatr Ann 2003;32:595-603.

5 Slattery MM, Morrison JJ: Preterm delivery. Lancet 2002;360:1489-1497.

6 Symington A, Pinelli J: Developmental care for promoting development and preventing morbidity in preterm infants. Cochrane Database Syst Rev 2006:CD001814.

$>7$ Cooper R, Atherton K, Power C: Gestational age and risk factors for cardiovascular disease: evidence from the 1958 British birth cohort followed to mid-life. Int J Epidemiol 2009;38:235-244.

8 Siewert-Delle A, Ljungman S: The impact of birth weight and gestational age on blood pressure in adult life. A population-based study of 49-year-old men. Am J Hypertens 1998;11:946-953.

$>9$ Kistner A, Celsi G, Vanpee M, Jacobson SH: Increased blood pressure but normal renal function in adult women born preterm. Pediatr Nephrol 2000;15:215-220.

10 Kistner A, Jacobson L, Jacobson S, Svensson E, Hellstrom A: Low gestational age associated with abnormal retinal vascularization and increased blood pressure in adult women. Pediatr Res 2002;51:675-680.

- 11 Doyle LW, Faber B, Callanan C, Morley R: Blood pressure in late adolescence and very low birth weight. Pediatrics 2003;111:252257.

-12 Bonamy AK, Martin H, Jorneskog G, Norman M: Lower skin capillary density, normal endothelial function and higher blood pressure in children born preterm. J Intern Med 2007;262:635-642.

13 Bonamy A, Bendito A, Martin H, Andolf E, Sedin G, Norman M: Preterm birth contributes to increased vascular resistance and higher blood pressure in adolescent girls. Pediatr Res 2005;58:845-849.

14 Hack M, Schluchter M, Cartar L, Rahman M: Blood pressure among very low birth weight $(<1.5 \mathrm{~kg})$ young adults. Pediatr Res 2005;58: $677-684$.

15 Johansson S, Iliadou A, Bergvall N, Tuvemo T, Norman M, Cnattingius S: Risk of high blood pressure among young men increases with the degree of immaturity at birth. Circulation 2005;112:3430-3436.
16 Dalziel S, Parag V, Rodgers A, Harding J: Cardiovascular risk factors at age 30 following pre-term birth. Int J Epidemiol 2007;36: 907-915.

17 Keijzer-Veen MG, Dulger A, Dekker FW, Nauta J, van der Heijden BJ: Very preterm birth is a risk factor for increased systolic blood pressure at a young adult age. Pediatr Nephrol 2010;25:509-516.

$\checkmark 18$ Rodriguez-Soriano J, Aguirre M, Oliveros $\mathrm{R}$, Vallo A: Long-term renal follow-up of extremely low birth weight infants. Pediatr Nephrol 2005;20:579-584.

19 Iacobelli S, Loprieno S, Bonsante F, Latorre G, Esposito L, Gouyon JB: Renal function in early childhood in very low birthweight infants. Am J Perinatol 2007;24:587-592.

20 Keijzer-Veen M, Schrevel M, Finken M, Dekker F, Nauta J, Hille E, Frolich M, van der Heijden B: Microalbuminuria and lower glomerular filtration rate at young adult age in subjects born very premature and after intrauterine growth retardation. J Am Soc Nephrol 2005;16:2762-2768.

21 Hinchliffe SA, Sargent PH, Howard CV, Chan YF, van Velzen D: Human intrauterine renal growth expressed in absolute number of glomeruli assessed by the disector method and Cavalieri principle. Lab Invest 1991;64: 777-784.

22 Gubhaju L, Black MJ: The baboon as a good model for studies of human kidney development. Pediatr Res 2005;58:505-509.

23 Hendrickx AG, Peterson PE: The baboon in embryology and teratology research; in VandeBerg JL, Williams-Blangero S, Tardif $\mathrm{SD}$ (eds): The Baboon in Biomedical Research. New York, Springer Science \& Business Media, 2009, pp 157-178.

24 Saxen L: Organogenesis of the Kidney. Cambridge, Cambridge University Press, 1987.

25 Bertram JF: Analysing renal glomeruli with the new stereology. Int Rev Cytol 1995;161: 111-172.

26 Nyengaard JR: Stereologic methods and their application in kidney research. J Am Soc Nephrol 1999; 10:1100-1123.

27 Rodriguez MM, Gomez AH, Abitbol CL, Chandar JJ, Duara S, Zilleruelo GE: Histomorphometric analysis of postnatal glomerulogenesis in extremely preterm infants. $\mathrm{Pe}$ diatr Dev Pathol 2004;7:17-25.

28 Hinchliffe SA, Sargent PH, Chan YF, van Velzen D, Howard CV, Hutton JL, Rushton DI: 'Medullary ray glomerular counting' as a method of assessment of human nephrogenesis. Pathol Res Pract 1992;188:775-782.

29 Bacchetta J, Harambat J, Dubourg L, Guy B, Liutkus A, Canterino I, Kassai B, Putet G, Cochat P: Both extrauterine and intrauterine growth restriction impair renal function in children born very preterm. Kidney Int 2009;76:445-452.
30 Cuzzolin L, Fanos V, Pinna B, di Marzio M, Perin M, Tramontozzi P, Tonetto P, Cataldi $\mathrm{L}$ : Postnatal renal function in preterm newborns: a role of diseases, drugs and therapeutic interventions. Pediatr Nephrol 2006; 21:931-938.

31 Thomson MA, Yoder BA, Winter VT, Martin H, Catland D, Siler-Khodr TM, Coalson JJ: Treatment of immature baboons for 28 days with early nasal continuous positive airway pressure. Am J Respir Crit Care Med 2004;169:1054-1062.

32 Gubhaju L, Sutherland MR, Yoder BA, Zulli A, Bertram JF, Black MJ: Is nephrogenesis affected by preterm birth? Studies in a nonhuman primate model. Am J Physiol Renal Physiol 2009;297:F1668-F1677.

33 Sutherland MR, Gubhaju L, Yoder BA, Stahlman MT, Black MJ: The effects of postnatal retinoic acid administration on nephron endowment in the preterm baboon kidney. Pediatr Res 2009;65:397-402.

34 Gundersen HJ: Stereology of arbitrary particles. A review of unbiased number and size estimators and the presentation of some new ones, in memory of William R. Thompson. J Microsc 1986;143:3-45.

35 Gundersen HJ, Jensen EB: The efficiency of systematic sampling in stereology and its prediction. J Microsc 1987;147:229-263.

>36 Hinchliffe SA, Lynch MR, Sargent PH, Howard CV, Van Velzen D: The effect of intrauterine growth retardation on the development of renal nephrons. Br J Obstet Gynaecol 1992;99:296-301.

37 Manalich R, Reyes L, Herrera M, Melendi C, Fundora I: Relationship between weight at birth and the number and size of renal glomeruli in humans: a histomorphometric study. Kidney Int 2000;58:770-773

38 Zaffanello M, Bassareo PP, Cataldi L, Antonucci R, Biban P, Fanos V: Long-term effects of neonatal drugs on the kidney. J Matern Fetal Neonatal Med 2010;23(suppl 3):87-89.

39 Shanks A, Gross G, Shim T, Allsworth J, Sadovsky Y, Bildirici I: Administration of steroids after 34 weeks of gestation enhances fetal lung maturity profiles. Am J Obstet Gynecol 2010;203:47.e1-47.e5.

40 Stonestreet BS, Hansen NB, Laptook AR, Oh W: Glucocorticoid accelerates renal functional maturation in fetal lambs. Early Hum Dev 1983;8:331-341.

41 al-Dahan J, Stimmler L, Chantler C, Haycock GB: The effect of antenatal dexamethasone administration on glomerular filtration rate and renal sodium excretion in premature infants. Pediatr Nephrol 1987;1:131135.

42 Jahnukainen T, Chen M, Berg U, Celsi G: Antenatal glucocorticoids and renal function after birth. Semin Neonatol 2001;6:351355 . 
43 Ervin MG, Seidner SR, Leland MM, Ikegami M, Jobe AH: Direct fetal glucocorticoid treatment alters postnatal adaptation in premature newborn baboons. Am J Physiol 1998;274:R1169-R1176.

44 Ervin M, Berry L, Ikegami M, Jobe A, Padbury J, Polk D: Single dose fetal betamethasone administration stabilizes postnatal glomerular filtration rate and alters endocrine function in premature lambs. Pediatr Res 1996;40:645-651.

45 van den Anker J, Hop W, de Groot R, van der Heijden B, Broerse H, Lindemans JS, Sauer PJ: Effects of prenatal exposure to betamethasone and indomethacin on the glomerular filtration rate in the preterm infant. Pediatr Res 1994;36:578-581.

-46 Kari M, Hallma M, Eronen M, Teramo K, Virtanen M, Koivisto M, Ikonen R: Prenatal dexamethasone treatment in conjunction with rescue therapy of human surfactant: a randomized placebo-controlled multicenter study. Pediatrics 1994;93:730-736.
47 Celsi G, Kistner A, Aizman Rea: Prenatal dexamethasone causes oligonephronia, sodium retention, and higher blood pressure in offspring. Pediatr Res 1998;44:317-322.

48 Ortiz LA, Quan A, Weinberg A, Baum M: Effect of prenatal dexamethasone on rat renal development. Kidney Int 2001;59:16631669.

49 Ortiz LA, Quan A, Zarzar F, Weinberg A, Baum M: Prenatal dexamethasone programs hypertension and renal injury in the rat. $\mathrm{Hy}$ pertension 2003;41:328-334.

50 Wintour EM, Moritz KM, Johnson K, Ricardo S, Samuel CS, Dodic M: Reduced nephron number in adult sheep, hypertensive as a re sult of prenatal glucocorticoid treatment. J Physiol 2003;549:929-935.

51 de Vries WB, van den Borne P, Goldschmeding $\mathrm{R}$, de Weger RA, Bal MP, van Bel F, van Oosterhout MF: Neonatal dexamethasone treatment in the rat leads to kidney damage in adulthood. Pediatr Res 2010;67:72-76.

52 Darlow BA, Graham PJ: Vitamin A supplementation for preventing morbidity and mortality in very low birthweight infants. CochraneDatabaseSystRev2002:CD000501.
53 Vilar J, Gilbert T, Moreau E, Merlet-Benichou C: Metanephros organogenesis is highly stimulated by vitamin A derivatives in organ culture. Kidney Int 1996;49:1478-1487.

54 Moreau E, Vilar J, Lelievre-Pegorier M, Merlet-Benichou C, Gilbert T: Regulation of c-ret expression by retinoic acid in rat metanephros: implication in nephron mass control. Am J Physiol 1998;275:938-945.

55 Lelievre-Pegorier M, Vilar J, Ferrier M-L, Moreau E, Freund N, Gilbert T, Merlet-Benichou C: Mild vitamin A deficiency leads to inborn nephron deficit in the rat. Kidney Int 1998;54:1455-1462.

56 Makrakis J, Zimanyi MA, Black MJ: Retinoic acid enhances nephron endowment in rats exposed to maternal protein restriction. $\mathrm{Pe}$ diatr Nephrol 2007;22:1861-1867.

57 Osathanondh V, Potter E: Development of human kidney as shown by microdissection. III. Formation and interrelationship of collecting tubules and nephrons. Arch Pathol 1963;76:290-302. 